\title{
INFORMAÇÃO E AMBIENTES ORGANIZACIONAIS: ENSAIO SOBRE A DINÂMICA DOS AMBIENTES INFORMACIONAIS NAS ORGANIZAÇÕES
}

\author{
Antonio Rodrigues de Andrade \\ Universidade Federal do Estado do Rio de Janeiro (UNIRIO)
}

Catarina Roseira

Faculdade de Economia da Universidade do Porto (FEP)

Aldo de Albuquerque Barreto

Universidade da Amazônia

\begin{abstract}
R e s u mo
O termo informação ganhou relevância preponderante nas décadas finais do século passado, quando, a explosão informacional, potencializada pelas tecnologias emergentes, fez com que o seu tratamento ganhasse nova dimensão, devido ao seu ritmo cada vez mais crescente. A informação é um elemento fundamental das empresas que procuram a conquista da vantagem competitiva. Para utilizá-la de forma estratégica é importante saber que informações são adequadas, deixar as informações disponíveis e acessíveis, saber as informações relevantes, sua origem e a quem endereça-las e que sua transmissão seja intensa atendendo aos níveis de pertinência desejados. Entretanto, sua utilização pode não receber a devida atenção o que acarretará prejuízos tanto a eficiência quanto à eficácia organizacional. Considerando a relevância da informação, os ambientes informacionais, bem como a importância dos fluxos de informação para as Organizações, sejam elas públicas ou privadas, desenvolve-se este ensaio procurando apresentar, refletir e a provocar outras considerações e estudos a respeito da relação entre o ambiente organizacional e o ambiente informacional. Apresenta, ainda, conceitos de conjugação dos ambientes organizacional e informacional, bem como a sua dinâmica nas Organizações.
\end{abstract}

Palavras-chave: Informação. Fluxo de informação. Ambiente organizacional. Ambiente informacional.

\section{INFORMATION AND ORGANIZATIONAL ENVIRONMENTS: ESSAY ON THE DYNAMICS OF INFORMATIONAL ENVIRONMENTS IN ORGANIZATIONS}

\begin{abstract}
The term information gained major relevance in the final decades of the last century, when the information explosion, boosted by emerging technologies, made its treatment gain a new dimension, due to its everincreasing pace. Information is a key part of companies seeking to gain competitive advantage. To use it in a strategically form is important to know what kind of information is suitable, make it available and accessible, know the most relevant information, its origin and to whom address it and its transmission should be intense in view of the desired pertinence levels. Meanwhile, its use might not receive the due attention, what will cause losses in both efficiency and organizational effectiveness. Considering the relevance of the information, the
\end{abstract}


information environments, as well as the importance of information flows for organizations, whether they are public or private, this essay was developed seeking to present, reflect and promote other considerations and works regarding the relationship between the organizational and informational environments. It also presents concepts of mixed organizational and informational environments, as well as its dynamics in organizations.

Keywords: Information. Information flow. Organizational environment. Informational environment.

\section{Introdução}

O termo informação ganhou relevância preponderante, principalmente, nos negócios nas décadas finais do século passado quando a explosão informacional potencializada pelas tecnologias emergentes fez com que o seu tratamento ganhasse nova dimensão devido ao seu ritmo cada vez mais crescente.

A necessidade de investigação de suas propriedades e o seu comportamento, as forças que regem seu fluxo e os métodos para processá-la, a fim de obter acessibilidade e utilização ótimas, ganhou importância, muitas vezes, vital para a tomada de decisão e desenvolvimento de ações, tanto operacionais quanto estratégicas. Isto se aplica a todos os setores. $\mathrm{Na}$ forma sistemática do tratamento da informação está a base para criar significado, construir conhecimento e tomar decisões que permitam o desenvolvimento das Organizações.

A informação pode ser considerada como um importante instrumento para promover conhecimento e, em decorrência disto, favorecer o desenvolvimento de novos hábitos. Harmonizar o processamento de difusão da informação deve, portanto, se constituir em meta para aqueles que trabalham com prestação de serviços, onde a informação é um pilar importante no estabelecimento das relações que visam adequar serviços oferecidos à demanda dos usuários e o retorno parece ser seguro, não só na conquista de novos clientes, como na melhoria dos serviços e, consequentemente, na sua satisfação e, ainda, na oportunidade de uma gestão, em parte, alicerçada pela informação.

O ambiente informacional e seu fluxo da informação ganha importância, considerado este contexto. Com as tecnologias da informação incorporadas, os fluxos da informação na empresa tendem a se tornar mais efetivos em virtude da elevação da capacidade de coletar, estocar, processar e transferir informações, o que torna possível a obtenção de uma maior velocidade na comunicação, redução no prazo de respostas às variações dos ambientes, tanto interno quanto externo, e melhoria da tomada de decisão; enfim, permite um aumento da eficiência organizacional em vários aspectos.

Davenport (1998) na sua proposta da ecologia da informação apresenta variáveis que compõe o ambiente informacional de uma organização, no qual define que os tomadores de 
decisão necessitam ter um olhar holístico sobre as informações que permeiam este ambiente.

Para Davenport (1998), o ambiente informacional está relacionado com o ambiente organizacional e com o ambiente externo da empresa.

No ambiente organizacional, variáveis como a situação dos negócios, os investimentos em tecnologia e a distribuição física repercutem no ambiente informacional. Por outro lado, aspectos como competitividade, existência ou não de soluções de tecnologia da informaçõ disponíveis e tipos de informações comercializadas exercem influência no ambiente informacional interno (POPADIUK, FRANKLIN, MIYABARA, GARDESANI, 2005).

Todas as Organizações possuem um microambiente que fazem parte de um macro ambiente informacional (DAVENPORT, 1998). Esses microambientes formam um ecossistema que é formado por três ambientes: o informacional, o organizacional e o externo. Considerando os três ambientes pode-se melhor compreender os cenários e contextos em que as informações são coletadas, analisadas e a decisão é tomada.

Além de Davenport (1998), outros autores merecem destaque ao considerar o ambiente organizacional como um ecossistema tendo na informação seu elemento principal, são eles: McGee e Prusak (1998) e Choo (1998; 2003).

Por fim, encontra-se na informação o elemento que figura como fio condutor para a integração organizacional. O alinhamento da organização tendo na informação o elemento condutor busca promover a harmonia entre os ambientes organizacionais e seus espaços informacionais tanto internamente (intra-ambientes organizacionais) quanto na transferência de informações entre eles (inter-ambientes organizacionais) de forma ajustada as necessidades e demandas específicas de cada ambiente. É atribuição dos espaços informacionais por meio dos fluxos de informação prover o atendimento a demanda informacional tanto inter quanto intra-ambientes organizacionais.

Considerando a relevância dos ambientes informacionais, bem como a importância dos fluxos de informação para as Organizações, sejam elas públicas ou privadas, desenvolveu-se este ensaio procurando apresentar, refletir e a provocar outras considerações e estudos a respeito da relação entre o ambiente organizacional e o ambiente informacional. Apresenta, ainda, conceitos de conjugação dos ambientes e sua dinâmica nas Organizações.

\section{Informação e ambiência organizacional}

O mundo é composto por signos, informações puras, fazendo com que toda a economia seja um processamento de informações. Cabem as Organizações processarem a 
informação a fim de planejar, organizar, coordenar e controlar suas atividades e tomar decisões.

A informação em si está desempenhando um papel cada vez mais importante no comércio mundial. As organizações são máquinas de processamento de informação. Neste sentido, o fluxo da informação tem importância e deve tornar-se mais efetivo em coletar, armazenar, processar e transferir informações, o que torna possível uma melhor comunicação. Se suportada pela tecnologia adequada pode, ainda, proporcionar a redução no prazo de respostas às variações dos ambientes, tanto interno quanto externo e, aprimoramento na tomada de decisão. Enfim, pode contribuir para a melhoria da qualidade e da produtividade organizacional em vários aspectos.

Por ser um sistema aberto e probabilístico o complexo organizacional depende do desenvolvimento de sensibilidade para captar as mudanças ambientais, sociais, econômicas, políticas e tecnológicas e a executar a adaptação necessária para garantir a sua sobrevivência e, principalmente, a sua evolução por meio da incorporação da informação e, ainda, dar-lhe sentido nas ações do dia a dia não só para as rotinas como, também, em uma perspectiva estratégica.

Está no fluxo de informação a articulação entre os vários agentes das ações Organizacionais. Sendo uma sucessão de eventos, desde o processo de mediação, entre a geração da informação por uma fonte emissora, e a aceitação da informação pela entidade receptora, até a realização da geração de conhecimento no indivíduo e no seu espaço de convivência (BARRETO, 2000).

Toda empresa é um sistema em que recebe entradas que são processadas e promovem uma saída de acordo com os objetivos da organização. O processamento ocorre baseado em um ciclo operacional, que para efeito deste trabalho, tem início na solicitação de um cliente e é concluído quanto ele é atendido.

A eficiência da empresa será avaliada em consonância com dois aspectos: o primeiro refere-se à velocidade de execução do ciclo e o segundo relaciona-se com os custos envolvidos para a sua realização. Portanto, a empresa será tão mais eficiente quanto maior a sua velocidade em executar o ciclo operacional, bem como quanto menores forem os custos envolvidos.

O ciclo operacional, aqui considerado, envolve atividades tais como vendas, operação e entrega e é viabilizado pelos fluxos de informação que promovem a geração e o tratamento das informações decorrentes da execução das atividades. A relação entre atividades e 
informação é total. Enquanto, por um lado, as informações ativam as atividades, por outro as atividades produzem informações que provocam novas atividades ou servem de medidas do que foi realizado.

Modificar um fluxo de informação significa intervir na organização efetuando uma mudança em seu estado. Toda organização é composta por três subsistemas básicos, conforme a saber: o subsistema técnico é composto de tecnologias, equipamentos e métodos de trabalho, o subsistema social é composto pela estrutura de relacionamento entre as pessoas e, por fim, o subsistema político é composto pelas estruturas organizacionais e pelas relações de poder entre os seus participantes. Portanto, ao buscar a eficiência operacional, a empresa não deve estar preocupado especificamente com um fluxo de informação e sim com o conjunto integrado de fluxos que suportam e integram as atividades de uma organização em seus vários níveis.

No contexto de uma organização, os fluxos de informação devem ser construídos a fim de atender às necessidades dos diversos níveis e das diversas atividades da organização. Quanto às atividades, as empresas buscam operacionalizá-las considerando dois enfoques: o primeiro mecanicista e o segundo orgânico. As Organizações possuem modelos de gestão que podem variar entre dois limites sendo o primeiro denominado toyotismo, onde apresenta um novo paradigma produtivo decorrente das transformações sócio-técnicas das empresas, pela intercessão do novo padrão tecnológico baseado na microeletrônica e nas tecnologias da informação e outro que é denominado mecanicismo, onde as empresas se comparam ao fordismo, sendo o posto do toyotismo.

Esses extremos formam um contínuo em que as empresas se posicionam e organizam seus processos produtivos. Enquanto o mecanicista conduz a um controle vertical, o orgânico conduz a um controle horizontal. A existência de um ou outro enfoque na empresa contribui para a manutenção de formas diferentes de funcionamento dos fluxos de informação, bem como do uso das tecnologias de informação.

Quanto aos níveis, em geral, as organizações diferenciam-se em três níveis organizacionais onde executam as ações, qualquer que seja a natureza ou tamanho da organização, são eles: o Operacional - relacionado com os problemas de desempenho eficaz sendo dirigido para as exigências impostas pela natureza da tarefa técnica; o Gerencial gerencia as atividades do nível operacional, mediando as fronteiras ambientais e administrando as tarefas técnicas a serem desempenhadas; e o Institucional - constitui-se na 
fonte do significado e da legitimação que possibilita a consecução dos objetivos organizacionais.

Tendo em vista a natureza diferenciada de cada nível, os fluxos de informação devem produzir respostas que atendam às necessidades de cada um de seus níveis, sem se esquecer, contudo, de atender as exigências pertinentes à integração dos três níveis.

Os fluxos de informação institucionais devem gerar informação que possibilitam observar as variáveis presentes nos ambientes externo e interno, com a finalidade de monitorar e avaliar o desempenho, o planejamento e as decisões de alto nível. Os fluxos de informação gerencial devem permitir a geração de informações das variáveis presentes nos ambientes externo e interno, monitorar e avaliar seus processos, o planejamento e a tomada de decisão de nível gerencial. Por fim, os fluxos de informação operacional devem possibilitar a geração de informações que permitam executar as suas atividades e tarefas, monitorar o espaço geográfico sob sua responsabilidade, o planejamento e a tomada de decisão de nível operacional.

Consideradas as dimensões, no que se refere às atividades e aos níveis organizacionais, três grandes aspectos analíticos se configuram: o primeiro refere-se à disponibilidade de informações para os procedimentos operacionais das unidades produtivas; o segundo refere-se com as necessidades estratégicas das empresas e, por fim, o terceiro, refere-se com a natureza sistêmica das Organizações onde devem ser capazes de servir aos interesses intra e inter empresas.

Por fim, cabe destacar, que estes aspectos, citados anteriormente, sejam isoladamente ou de forma integrada, possuem escalas diferentes de prioridades dentre as empresas mecanicistas e toyotista.

\section{Ambientes informacionais}

As organizações possuem distintos ambientes informacionais que são constituídos por fluxos de informação que perpassam a ação do indivíduo no contexto do trabalho que são as atividades, as tarefas e as tomadas de decisão. Compreende-se como ambiente informacional os espaços de interação das pessoas, tecnologias, e informação voltada aos objetivos organizacionais (VALENTIM, 2010).

Para Choo (2003), a gestão da informação é "a gestão de uma rede de processos que adquire, cria, organiza, distribui e utiliza a Informação" (CHOO, 2003, 20). Sordi (2008) 
complementa afirmando que a administração da informação nas Organizações é a chave para a integração dos diversos componentes que dão forma ao ambiente organizacional, criando a comunicação necessária à prática administrativa que é desenvolvida para atender às expectativas de quem as solicita.

O ambiente informacional, como visto, é entendido como os espações de atuação responsáveis pela cotidiana dinâmica organizacional são, portanto, resultantes dos ambientes organizacionais, cujo enfoque é a informação. São os fluxos de informação o elemento fundamental dos ambientes informacionais e não há ambiente informacional sem haver fluxo de informação e vice-versa. (VALENTIM, 2010)

Resumidamente, os ambientes informacionais são um conjunto agregado de indivíduos, sistemas e organizações que captam, processam e disseminam informações. Conforme os níveis organizacionais podem ser encontradas ações correlacionadas que se desenvolvem em cada espaço específico, mas que devem se integrar na organização, conforme proposto por Valentim (2010). São elas:

a. No nível estratégico, o ambiente organizacional é responsável pelo desenvolvimento das políticas, planejamento, tomada de decisão estratégica e o estabelecimento de estratégias. Correspondendo ao ambiente organizacional encontra-se o ambiente informacional que está diretamente relacionado a esses saberes e fazeres que necessitam de informação estratégica, informações de prospecção e o monitoramento do mercado e da concorrência e, ainda, a informação voltada para a relação com o cliente.

b. O nível tático encontrasse o ambiente organizacional voltado para o estabelecimento de cronograma de atividades, acompanhamento de custos, controle de qualidade e o correspondente ambiente informacional que se volta para informações, para o desempenho das atividades e tomadas de decisão de médio e curto prazo. Nesse contexto, a informação tecnológica, a informação financeira, as informações comerciais entre outras são fundamentais para que haja a efetividade das atividades desenvolvidas.

c. Por fim, o nível operacional, o ambiente organizacional relacionado com a execução das atividades, cumprimento dos padrões e procedimentos, dentre outros. Para o seu ambiente informacional correspondente às informações direcionam-se para a base da execução do trabalho na execução das atividades/tarefas desempenhadas. 
Contudo, cabe um alerta, a configuração organizacional pode se tornar grande influenciadora da existência dos fluxos de informação considerando que a forma como se manifestam o sistema de responsabilidade, de autoridade e de comunicação podem atuar de maneira distinta de organização para organização. Dessa forma, procurar entender os fluxos de informação baseado na estrutura organizacional exposto no organograma da Organização pode é um equívoco que procurar evitar.

Os fluxos de informação trafegam pela organização com estruturas informacionais (dados ou informação) de modo a possibilitar a construção do conhecimento nos seus participantes. Assim, cada um dos níveis organizacionais produz informações e, portanto, fluxos de informação distintos, cuja aplicação é diversa e dependerá essencialmente dos conteúdos informacionais produzidos, dos objetivos para que foram produzidos, bem como dos objetivos de uso por parte das pessoas e setores que atribuirão importância e pertinência a informação.

Acrescente-se que cada um dos níveis organizacionais possui necessidades e demandas específicas o que pode provocar novos contornos organizacionais gerando nova disposição e alocação de seus participantes e distribuição de trabalho.

Encontra-se, ainda, em Moraes e Fadel in Valentin (2010) que o principal objeto de estudo dos fluxos de informação nas organizações deve ser a própria informação. As autoras tomam o entendimento que uma vez que a informação é um elemento chave para o desempenho das organizações podem subsidiar as tomadas de decisão e influenciar o comportamento das pessoas.

Nos estudos que envolvem a informação no âmbito organizacional, a informação, como já mencionado, vem sendo considerada insumo básico para agregar valor às atividades organizacionais direcionadas para a melhoria dos resultados. Dessa forma, a organização que melhor compreender que a informação, uma vez captada, gerenciada, organizada, tratada e disseminada de forma a atender as demandas e necessidades organizacionais adequadamente, sendo considerada como um recurso importante tanto quanto os demais da organização, possibilitará a melhoria da produtividade, do desempenho organizacional e da competitividade. (CARVALHO in VALENTIN, 2010). 


\section{Dinâmica informacional nas organizações}

As organizações empresariais são sistemas que vivem em constante interação com o seu respectivo ambiente. As organizações adquirem, processam e agem com a informação que é extraída do ambiente. O processamento da informação permite que as organizações gerem novo conhecimento e avaliem o respectivo ambiente baseado na interpretação das informações obtidas. Dessa forma, a informação passa a ser determinante no processo de inovação e, em particular, na inovação tecnológica. Fluxos de informação imperfeitos bem como ambientes pobres em informação são limitantes da inovação e da mudança nas organizações. (ANDRADE, 2007).

A organização empresarial de qualquer natureza, gênero ou propósito, tem que estar em constante atualização devido à aceleração das descobertas tecnológicas e das evoluções socioculturais, nesse contexto, e a informação pode ser vista como um recurso importante para a adaptação da organização ao seu ambiente.

Não há gestão possível sem informação e ao lado de funções tradicionais, a empresa deve incorporar a função informacional. Como uma função de caráter transversal, não se limita somente ao ambiente interno da organização. Percorre órgão a órgão de uma forma transversal, para ligando-os entre si e ao ambiente externo. Assim uma nova função a ser exercida pela Administração que é a Gestão da Informação. (ANDRADE; BARRETO, 2015).

A Gestão da Informação é uma ação sistêmica de procurar entender as necessidades informacionais de uma empresa e disponibiliza-las para a solução de seus problemas. Para que

o gerenciamento da informação seja eficaz, eficiente e efetivo no cumprimento de seu objetivo deve se saber com clareza o que é a informação para a empresa, quem a possui, como

é conservada, quem é o responsável pelo gerenciamento, como controlar e utilizar a informação.

Para a sustentação e o crescimento da relação existente entre sistema organizacional e meio ambiente há a necessidade de um processo pelo qual a organização se informa sobre ela própria e sobre o seu ambiente e, ainda, informa o ambiente sobre ela própria, isto implica em: criação, comunicação, tratamento e memorização da informação. Além disso, o processo deve produzir resultados que permitam avaliar a qualidade da informação, sobre a sua quantidade, sobre o custo e o tempo de geração, bem coma sua utilidade para o usuário. Por esses motivos, a informação é um instrumento de gestão importante e uma vez reconhecida como tal, tem que ser gerenciada. 
Além do gerenciamento da informação, o monitoramento e a percepção do ambiente significam identificar, descrever e interpretar a informação do ambiente organizacional para criar um entendimento efetivo desse ambiente com suas necessidades, demandas e oportunidades.

Monitorar o ambiente e gerenciar a informação significa captar, aprender, guardar, recuperar e utilizar as informações e os conhecimentos construídos e quanto melhor forem as condições da sua organização, maior será a efetividade do processo.

As informações gerenciadas e em condições de acesso a todos servirão para que cada um, independentemente do seu contexto de atuação na organização, saiba qual fonte e como recuperar e interagir com a informação no seu processo de trabalho e nas decisões que lhe afetam.

Toda ação tem sua origem na informação e na dinâmica informacional que a sustenta nas organizações. Possui movimentações (comunicação) que ocorrem entre os vários ambientes organizacionais denominadas de coesão informacional e acoplamento informacional.

Figura 1 - Ambiente organizacional

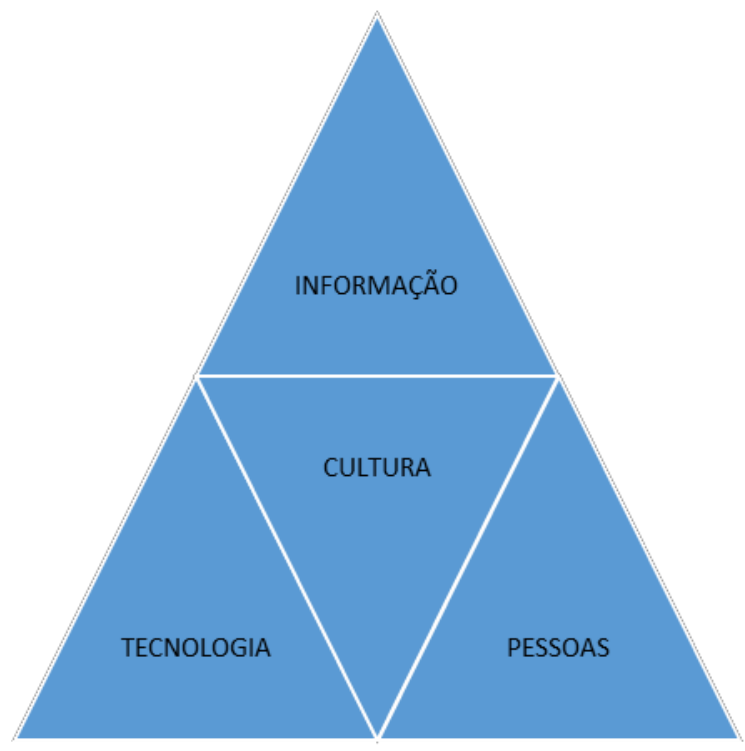

Os ambientes organizacionais mantem relação correspondente aos modelos de gestão. Os níveis organizacionais existentes correspondem aos espaços em que pessoas, informação e tecnologia se relacionam, considerando a cultura organizacional predominante, e devem direcionar-se para os objetivos organizacionais. O ambiente organizacional variará conforme o modelo de gestão, conforme mencionado, no caso do modelo mecanicista, por 
exemplo, os fluxos de informação são verticais, enquanto no toyotismo são horizontais.

A coesão informacional é interna a um ambiente e acontece quando existe consistência na informação e seus fluxos no ambiente organizacional medindo, portanto, a integridade das informações dentro de cada ambiente e o sentido que ela tem para a realização das operações e tomada de decisões que ocorrem no ambiente organizacional específico. No caso do modelo mecanicista a coesão pode ser identificada em um órgão ou unidade administrativa, enquanto, no modelo toyotista será encontrada em times de trabalho ou em processos de negócio se a organização adota a abordagem por processos.

Internamente ao ambiente organizacional podem existir centros de decisão, centros de informação e núcleos de operação. $O$ centro de decisão consiste de um ou mais tomadores de decisão, procedimentos de decisão e de ações para as quais decisões podem ser tomadas. O centro de informação e onde as ações no mundo real acontecem com a captura, processamento, retenção, recuperação e disseminação da informação resultante. No modelo mecanicista o decisor é único considerando sua característica de centralização, enquanto no toyotista podem ser encontradas com maior frequência decisões participativas.

São nos centros de informação que os fluxos de informação se materializam e circulam internamente ao ambiente organizacional. Os fluxos de informação podem acontecer entre diferentes espaços informacionais para atender as exigências informacionais dos núcleos operacionais ou dos centros de decisão. No modelo mecanicista o centro de informação é único e os detentores da informação tendem a mantê-la fechada a ouros participantes. No modelo toyotista o centro de informação é abrangente não sendo caracterizado por uma unidade estática, a informação circula, o acesso é fácil e a disponibilidade e ampla.

O núcleo de operação consiste de um ou mais postos de trabalho onde as ações de realização do trabalho acontecem. No modelo mecanicista serão encontrados nos postos de trabalho, nos indivíduos ou em unidades administrativas com atividades e tarefas especializadas, homogêneas ocupadas por profissionais univalentes e especialistas no que executam. No modelo toyotista serão encontrados nos trabalhos com ênfase colaborativa, com participação de todos, pois o domínio de uma atividade não e de exclusividade de um único colaborador sendo, portanto mais flexível e ocupada por profissionais polivalentes.

O acoplamento informacional é externo ao ambiente organizacional e mede as conexões existentes entre ambientes informacionais. Ocorre quando há transferência de informação entre os ambientes organizacionais de forma que o emissor disponibilize e facilite o acesso à informação e que o receptor receba/capture/acesse todas as informações 
necessárias dentro dos padrões de usabilidade para o pleno desenvolvimento de suas ações na organização, ou seja, haja acesso e disponibilidade de informação. O compartilhamento entre os ambientes organizacionais pode ocorrer em todos os sentidos, tanto verticalmente, de cima para baixo, e de baixo para cima como horizontalmente, da esquerda para a direita e viceversa. Nota-se no modelo mecanicista maior rigidez de procedimentos e trocas de informações verticais conforme a hierarquia, fluindo para baixo informação de comando e para cima informação de controle. No modelo toyotista as informações são compartilhadas. Os ambientes organizacionais estão contidos de acordo com os níveis organizacionais: estratégico, tático e operacional.

No nível estratégico o centro de decisão direciona-se para decisões corporativas e são influenciadas tanto pelo macro-ambiente quanto pelo micro-ambiente ou ambiente de tarefa. Os problemas não são estruturados e as decisões não são programadas. A informação tende a ser não estruturada.

Os centros de informação tratam de informações que possam suprir os centros de decisão. Essas informações possuem variáveis na sua maioria desconhecidas, tendo em vista a instabilidade dos movimentos dos mercados e globalizados. Essa situação provoca a necessidade de capacitação do núcleo de operação em termos de metodologia, métodos, técnicas e ferramentas que permita municiar os centros de informações de condições adequadas para a geração de informações pertinentes para que os centros de decisão.

No nível tático, o centro de decisão direciona-se para as decisões a serem adotadas para os programas que a organização deve cumprir e para a implementação do plano estratégico. As decisões são tanto programadas quanto não programadas. Os problemas são semiestruturados possuindo aspectos conhecidos e outros desconhecidos quanto as variáveis que o compõe e as decisões podem ser tanto programadas quanto não programadas. Os centros de informação tratam de informações semiestruturadas com variáveis conhecidas e outras não, o que implica em um nível de acompanhamento e controle com indicadores de desempenho que permitam a obtenção de informações mais consistentes.

Esta situação faz com que o núcleo operacional se preocupe com as informações internas que dependam da própria organização.

No nível operacional as decisões são programadas e os centros de decisão adotam procedimentos regulares e na sua maioria com informações conhecidas o que faz com que o centro de informação tenha uma maior aproximação com o núcleo de operação. 
Figura 2 - Dinâmica informacional na organização

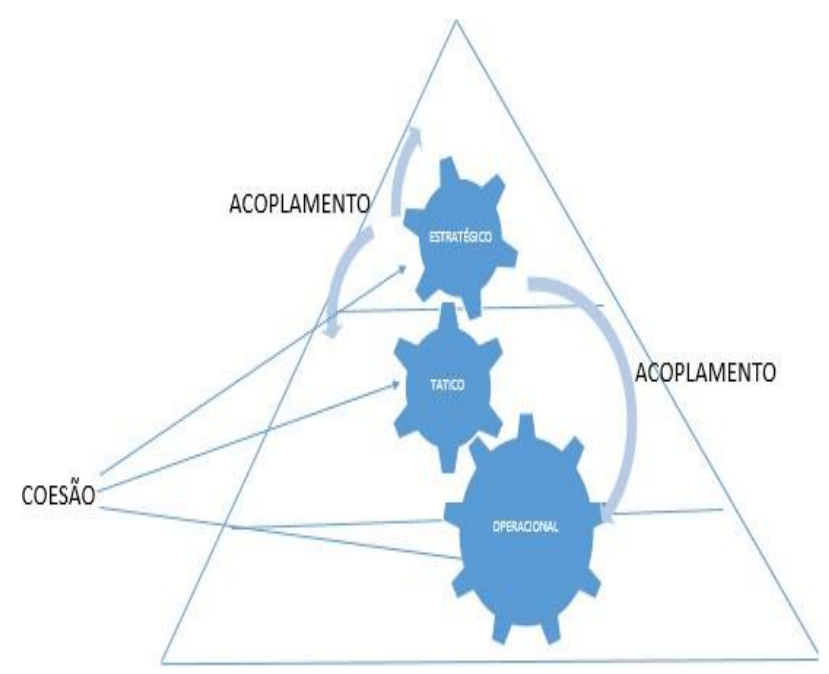

Tabela 1: Comparação entre Organizações orientadas por função e Organizações Orientadas por Informação

\begin{tabular}{|c|c|}
\hline ORIENTAÇÃO POR FUNÇÃO & ORIENTAÇÃO POR INFORMAÇÃO \\
\hline $\begin{array}{l}\text { Estrutura organizacional burocrática, } \\
\text { permanente, rígida e definida com } \\
\text { autoridade baseada na hierarquia e no } \\
\text { comando. }\end{array}$ & $\begin{array}{l}\text { Estrutura organizacional flexível, } \\
\text { mutável, adaptativa e transitória com } \\
\text { autoridade baseada no conhecimento e no } \\
\text { compartilhamento da informação. }\end{array}$ \\
\hline Processo decisório centralizado. & Processo decisório descentralizado. \\
\hline Comunicações verticais. & Comunicações circulares. \\
\hline $\begin{array}{l}\text { Desce fluxo de informação e sobe fluxo } \\
\text { de controle conforme a hierarquia. }\end{array}$ & $\begin{array}{l}\text { Informação e seus fluxos transitam } \\
\text { vertical e horizontalmente entre os } \\
\text { participantes. }\end{array}$ \\
\hline $\begin{array}{l}\text { Vê o ambiente de forma estável e } \\
\text { permanente. }\end{array}$ & $\begin{array}{l}\text { Vê o ambiente de forma instável e } \\
\text { dinâmica e compartilha informações. }\end{array}$ \\
\hline $\begin{array}{l}\text { Baixa ou indefinida coesão e baixo } \\
\text { acoplamento. }\end{array}$ & Alta coesão e alto acoplamento. \\
\hline Centros de decisão unitários. & Centros de decisão plurais. \\
\hline $\begin{array}{l}\text { Centros de Informação provedores de } \\
\text { informação. }\end{array}$ & $\begin{array}{l}\text { Centros de Informação como suporte aos } \\
\text { centros de decisão. }\end{array}$ \\
\hline
\end{tabular}


A cultura organizacional entendida como um conjunto de crenças, valores e tradições existentes na empresa disciplinam e até mesmo, regulam e condicionam o funcionamento da organização influenciando o comportamento dos principais agentes da informação: as pessoas. Observa-se que a dinâmica informacional tem um padrão de comportamento conforme o ambiente organizacional, contudo poderá variar de organização para organização na forma como interagem a tecnologia, as pessoas e a informação, de acordo com a cultura organizacional.

Por fim, pode-se estabelecer uma diferença entre os modelos de gestão mecanicista que possui uma orientação por função e o modelo de gestão toyotista e que tendem a uma orientação por informação conforme a Tabela 1 .

\section{Considerações finais}

Este ensaio abordou a dinâmica das organizações sob a perspectiva da informação. Abordou a informação, os ambientes organizacionais e os ambientes informacionais. Avaliou a existência de dois aspectos para o desenvolvimento de ações relacionadas à integração organizacional: o primeiro, referente ao alinhamento externo que considera a empresa em relação ao seu ambiente de atuação onde procurará abordar a questão da vantagem competitiva com ênfase no poder do mercado; o segundo refere-se ao alinhamento interno que considera a manutenção dos elementos internos durante a implementação da estratégia. Este artigo deu mais ênfase ao segundo quanto ao tratamento interno da informação nas organizações.

Neste contexto, a informação desempenha papel essencial na integração das etapas, onde: (a) a informação na definição estratégica cria as condições para uma resposta competitiva mais eficaz da organização às exigências do ambiente; (b) a informação para a execução estratégica está relacionada à disseminação das definições estratégicas por toda a organização e contribuição para a criação das condições para a sua implementação; e (c) o feedback da informação sobre o desempenho permite que se reconheçam as necessidades de modificações e ajustes nas definições quando se tornarem ineficazes. (ANDRADE, 2007).

Concluindo, toda organização empresarial é um sistema aberto. Está inserida em um ambiente dinâmico que compreende outros sistemas e que, muitas vezes, devido às múltiplas relações entre ambiente e sistema, torna-se difícil a clara definição de suas fronteiras. Possui objetivos claramente definidos e subsistemas em constante interação que necessitam de 
integração. Para que isso se concretize um modelo de gestão adequado é fundamental. de forma a proporcionar o ajuste adequado à integração e ao alinhamento entre as variáveis organizacionais e a seus ambientes informacionais de forma a permitir e a assegurar o compartilhamento de informações com conectividade, acessibilidade e disponibilidade.

\section{Agradecimentos}

À CAPES - Coordenação de Aperfeiçoamento de Pessoal de Nível Superior, pelo financiamento do projeto que deu origem a este artigo (Processo BEX 6175/14-7).

\section{REFERÊNCIAS}

ANDRADE, R. A. A informação como suporte para o planejamento e para a formulação de políticas no setor de transportes. 2007. 234 f. Tese (Doutorado) - Curso de Engenharia de Transportes, COPPE/UFRJ, Universidade Federal do Rio de Janeiro, Rio de Janeiro, 2007.

ANDRADE, A. R; A BARRETO, A. Alinhamento estratégico nas organizações: a informação como elemento integrador de propósito, processos e pessoas. DataGramaZero: revista de Ciência da Informação, Rio de Janeiro, v. 16, n. 1, fev. 2015.

BARRETO, A.A. Os agregados de informação: memórias, esquecimento e estoques de informação. DataGramaZero: revista de Ciência da Informação, Rio de Janeiro, v. 1, n. 3, 2015.

CARVALHO, E. L. de. Importância da gestão da informação para o processo decisório nas organizações. In: VALENTIM, M. L. P. (Org.). Informação, conhecimento e inteligência organizacional. Marília: FUNDEPE Editora, 2010.

CHOO, C. W. Information management for the inteligent organization: the art of scanning the enviroment. Medford: Information Today, 2002.

CHOO, C. W. A organização do conhecimento: como as organizações usam a informação para significado, construir conhecimento e tomar decisões. São Paulo: Senac, 2003.

DAVENPORT, T. H. Ecologia da informação. São Paulo: Futura, 1998. 
McGEE, J; PRUSAK, L. Gerenciamento estratégico da informação. Rio de Janeiro: Campus, 1994.

MORAES, C. R. B. de; FADEL, B. A interface entre o comportamento organizacional e o informacional. In: VALENTIM, Marta (Org.). Ambientes e fluxos de informação. São Paulo: Cultura Acadêmica, 2010.

POPADIUK, S., FRANKLIN, M. A., MIYABARA, W. GARDESANI. Ambiente informacional e desempenho competitivo na indústria de autopeças para veículos. Revista Produção, Santa Catarina, v. 15, n. 3, p. 390-403, set./dez. 2005. Disponível em: < http://www.scielo.br/scielo.php?script=sci_arttext\&pid=S010365132005000300009\&lng=pt\&tlng=pt. 10.1590/S0103-65132005000300009>. Acesso em: 15 de maio de 2015.

SORDI, J. O. de. Administração da Informação: fundamentos e práticas de uma nova gestão do conhecimento. São Paulo: Saraiva, 2008.

VALENTIM, M. (Org.). Ambientes e fluxos de informação. São Paulo: Cultura Acadêmica, 2010. 